\title{
Application of Artificial Neural Networks for Maximal Power Point Tracking
}

\author{
Amadou Fousseyni Toure ${ }^{1,2, \text { * }}$, Fadaba Danioko ${ }^{2}$, Badie Diourte ${ }^{2}$ \\ ${ }^{1}$ Institut of Sciences Appliques, University of Sciences Techniques and Technologies, Bamako, Mali \\ ${ }^{2}$ Faculty of Science and Techniques, University of Sciences Techniques and Technologies, Bamako, Mali
}

Email address:

amadatoure@yahoo.fr (A. F. Toure), badiediourte@yahoo.fr (B. Diourte)

${ }^{*}$ Corresponding author

To cite this article:

Amadou Fousseyni Toure, Fadaba Danioko, Badie Diourte. Application of Artificial Neural Networks for Maximal Power Point Tracking. International Journal of Sustainable and Green Energy. Vol. 10, No. 2, 2021, pp. 40-46. doi: 10.11648/j.ijrse.20211002.12

Received: April 6, 2021; Accepted: April 26, 2021; Published: May 8, 2021

\begin{abstract}
In this paper, a hybrid controller of maximum power point tracking of photovoltaic systems based on the artificial neuron network has been proposed and studied. The data needed for model generation are obtained from the series of measurements. The training of neural networks requires two modes: the off-line mode to get optimal structure, activation function and learning algorithm of neural networks and in an online way these optimal neural networks are used in the PV system. The hybrid model is made up of two neural networks; the first network has two inputs and two outputs; the solar irradiation and the ambient temperature are the inputs; the outputs are the references voltage and current at the maximal power point. The second network has two inputs and one output; the inputs use the outputs of the first network, and the output will be the periodic cycle which controls the DC/DC converter. The performance of the method is analyzed under the different conditions of climatic variation using the MATLAB/Simulink simulation tool. A we compared our proposed method to the perturbation and observation approach, in terms of tracking accuracy, steady state ripple and response time.
\end{abstract}

Keywords: PV System PV, MPPT controller, Artificial Neural Networks, MATLAB/Simulink

\section{Introduction}

Since the power capacity by a generator is relatively low and cost's energy is relatively high; we will have a strong demand to increase the efficiency in order to reduce the energy production cost of photovoltaic and its optimization. However, the disadvantage of solar power production is that the generation of energy is not constant during the day because it changes with climatic conditions according to Ahmed and al. [1]. Besides, the conversion efficiency of solar energy to electric power is very low, only in 9 to $17 \%$ in vulnerable regions of irradiation, [2]. Despite its simple shape, the operating point oscillates near the Maximum Power Point (MPP), which leads to a loss energy and a tracking time relatively long, and, the operating point changes curve due variations climatic conditions (solar irradiation and ambient temperature) [3]. These generate losses in the MPP tracking; for example, the algorithm cannot identify the source of disturbance resulting from a variation in voltage or weather conditions. The perturbation and observation (P\&O) technique also require a control process system (such as software), which makes it challenging to integrate it into the PV panel [4]. An incremental conductance (InC) MPPT algorithm improving the $\mathrm{P} \backslash \& \mathrm{O}$ technique is presented in the study of Elgendy \& al. [5]. A modification of this InC algorithm, using a dynamic adaptation of the number of steps during MPP tracking process, is developed by Farhoodnea \& al. [6].

In the study of Sera $\&$ al. [7], it is shown by experimental tests that the incremental conductance and perturbation \& observation techniques have similar performances under dynamic and static conditions. The voltage-constant and current-constant methods also require a sensor for their implementation (that is to say, a voltage and current sensor, respectively), but the periodically opening of photovoltaic modules to measure new values of open circuit voltage and short-circuit current causes energy losses [8]. Using artificial intelligence techniques, the accuracy of the voltage and current prediction at the MPP is strongly dependent on the PV 
module temperature estimate's accuracy, which affects the output current and voltage (Is and Vt) [9]. The implementation of digital techniques is complex, considering the complexity of the current or voltage calculations at the MPP, a Digital Signal Processing (DSP) or a microcontroller is necessary for the realization these MPPT techniques; in addition, the time's response of the MPP tracking algorithm is low [10]. To avoid using a derivative to perform the maximal power point process, the derivative $\frac{\partial P_{P V}}{\partial V_{P V}}$ used in the perturbation \& observation method to detect the position of the MPP is replaced in the Ripple Correlation Control (RCC) method by a correlation function [11]. Another MPPT technique, maximum seek to control (ESC) having a self-optimization strategy is studied by Reisi et al. [12], it has the same operating principle that RCC MPPT. The RCC MPPT technique's performance depends on the precision of the correlation function's measurements $\mathrm{c}(\mathrm{t})$ [13]. The disadvantage of the MPPT technique ESC is that it requires the realization of a control circuit relatively complex [14].

In this paper, we use artificial neural networks for maximal power point tracking to improve the failures mentioned above. A hybrid MPPT comprises two neural networks is proposed; the first network has two inputs and two outputs; the solar irradiation and the ambient temperature are the inputs; the outputs are the references voltage and current at the maximal power point. The second network comprises one output and two inputs; the inputs use the first network's outputs, and the output will be the periodic cycle that drive the gate of the DC/DC converter. The data necessary for generating the ANN (Artificial Neuron Network) model is obtained from the series of measurements. The networks are developed first in offline mode to achieve optimal structure, activation function, learning algorithm of neural networks, and then these optimal RNA MPPT controllers are used in the PV system in online mode. The performance of our MPPT method is analyzed under the different conditions of climatic variation using the MATLAB/Simulink modeling and simulation tool and to test and valid the proposed neural networks.

\section{PV Operating Characteristics}

Although many environmental factors affect the operating characteristics of a photovoltaic cell and its electricity production, solar irradiation $\mathrm{G}$, measured in $\mathrm{W} / \mathrm{m}^{2}$, and temperature $\mathrm{T}$, measured in degrees Celsius $\left({ }^{\circ} \mathrm{C}\right)$ are the two factors the most affecting. PV operating characteristics as a function of these two factors can be modeled by mathematical equations.

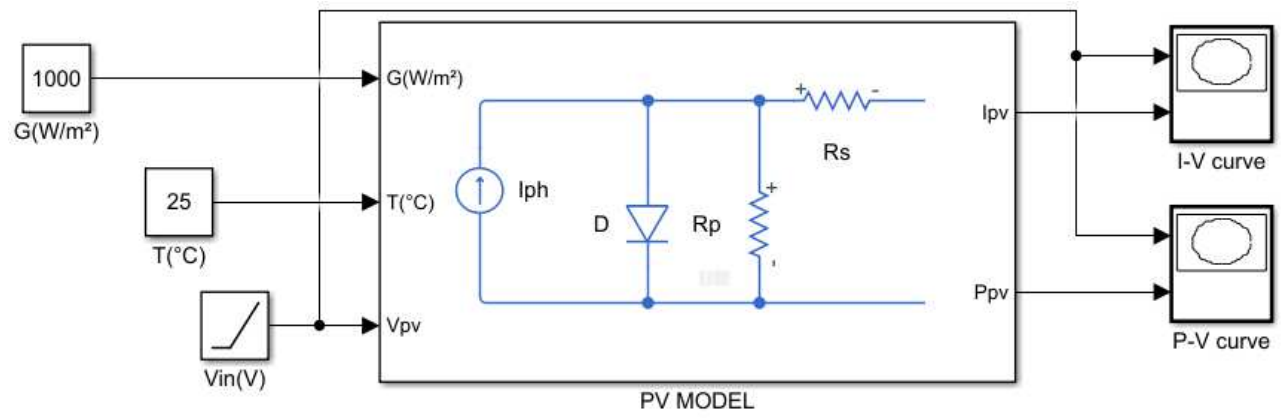

Figure 1. PV model implemented in Matlab/Simulink.

The source of photocurrent Iph depends on the solar irradiation and the ambient temperature through equation 1 [15]:

$$
I_{p h}(G, T)=\left[I_{s c n}+K_{i}\left(T-T_{n}\right)\right] \frac{G}{G_{n}}
$$

Iscn is the rated short-circuit current, $K i$ is the temperature coefficient, $G n$ is the rated solar irradiation, Tn is the rated ambient temperature of the cell, $\left(G n=1000 \mathrm{~W} \mathrm{~m}^{2}\right.$ and $T n=25^{\circ} \mathrm{C}$ in the normal temperature and pressure constant conditions $\mathrm{AM}=1.5$ ). We will be able to determine these values from the technical sheet for commercial photovoltaic cells or modules. The current Id and the voltage $V d$ of the diode are expressed by equations 2 et 3 [15]:

$$
I_{d}=I_{S}(T)\left[\exp \left(\frac{V_{P V}+I_{P V} \times R_{S}}{a V_{t}(T)}\right)-1\right]
$$

$I_{S}$ is the saturation current of the diode, a is the ideality constant of the diode, $V_{d}$ is the voltage of the diode, $V t$ is the semiconductor junction's thermal voltage.
The saturation current of the diode is a function of the temperature as follows equation 3 [15]:

$$
I_{S}(T)=\frac{I_{s c n}+K_{i}\left(T-T_{n}\right)}{\exp \left(\frac{\left.V_{o c n+K_{v}\left(T-T_{n}\right)}\right)-1}{a V_{t}(T)}\right)}
$$

Iscn is the rated short-circuit current, $K i$ is the voltage temperature coefficient.

The voltage's diode $V d$ is identical to the voltage of the photovoltaic module $V_{P V}$ for the ideal model. In addition, the thermal voltage $V t$ is expressed as a function of the temperature $T$ by equation 4 .

$$
V_{t}(T)=\frac{k T}{q} N_{S}
$$

$k$ is Boltzmann's constant $\left(1.3807 \times 10^{-23} \mathrm{~J} . K^{-1}\right)$, $q$ is charge's electric $\left(1.60217662 \times 10^{-19} C\right)$, $N_{S}$ the number of photovoltaic cells in series.

The current and the power output $\left(I_{P V} P_{P V}\right)$ of a photovoltaic module are respectively given by equations 5 
et $6[15,16]$ :

$$
\begin{gathered}
I_{P V}=I_{p h}(G, T)-I_{d}\left(T, V_{P V}\right)-\frac{V_{P V}+I_{P V} \times R_{S}}{R_{P}} \\
P_{P V}=V_{P V} \times I_{P V}
\end{gathered}
$$

$V_{P V}$, voltage's output of the PV source,

$I_{P V}$, current's output of the PV source,

$I_{p h}$, the photocurrent given by equation 1 ,

$I_{d}$, the diode current shown in equation 2 ,

$R_{P}, R_{S}$ are parallel and series resistances, respectively of the $\mathrm{PV}$ module.

Based on the PV current equation 5, it is clear that the PV output current is related to the solar irradiation $G$ and temperature $\mathrm{T}$.

Considering solar irradiation $\mathrm{G}$ and ambient temperature $\mathrm{T}$, equation 5 can be used to determine the current of a photovoltaic module as a function of a given voltage. These equations can also be obtained using basic algebra to determine the current of a photovoltaic module as a function

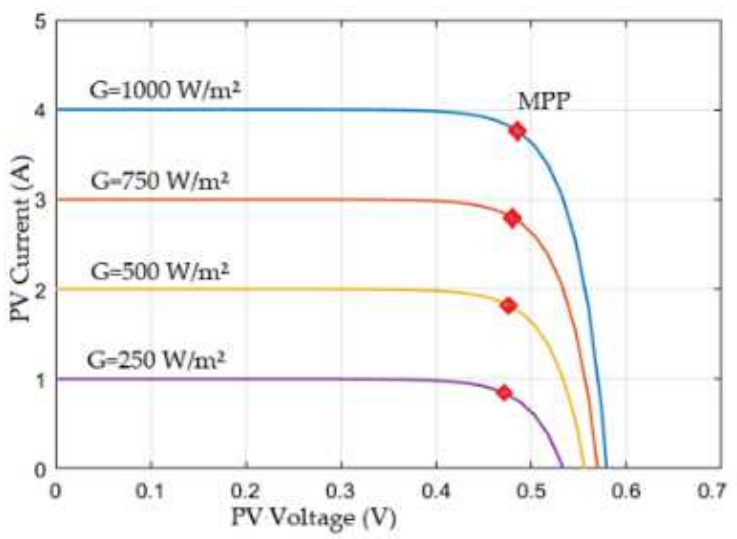

(a) of a given voltage in Figure 2 and Figure 3. The simplified model of a PV module can be modeled in Matlab/Simulink, shown in Figure 2 with the data from Table 1. Solar irradiation $\mathrm{G}$, temperature $\mathrm{T}$ and $\mathrm{PV}$ voltage $V_{P V}$ are the inputs; current $I_{P V}$ and $\mathrm{PV}$ power $P_{P V}$ are the outputs [15].

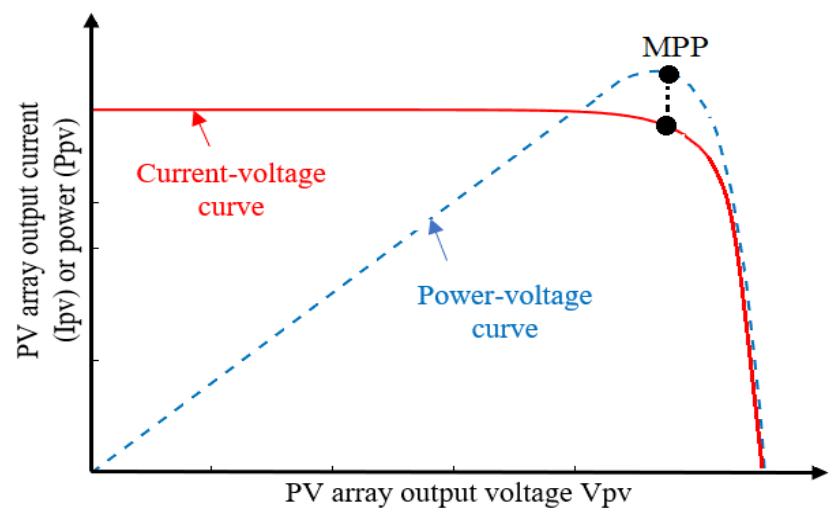

Figure 2. Curve of the current and power at the output of the module PV depending on the output voltage.

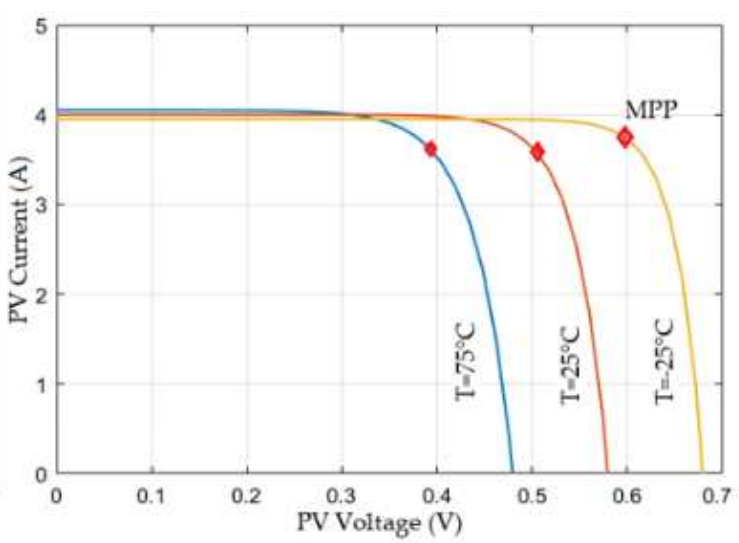

(b)

Figure 3. Variation of current and voltage of a PV module depending on the variation of solar irradiation (a) and ambient temperature (b).

Among the factors, solar irradiation and temperature are the factors that most affect the efficiency of a photovoltaic module. On the technical sheets of commercial photovoltaic modules, the efficiency is given under standard conditions (solar irradiation $G=1000 \mathrm{~W} / \mathrm{m}^{2}$ temperature $T=$ $25^{\circ} \mathrm{C} A M=1.5$ ). Figure 3 shows the dependence of the efficiency of a solar cell on variations in climatic conditions.

\section{Perturbation and Observation MPPT}

The MPPT method of Perturbation and Observation P\&O is based on the property that the derivative of the power-voltage characteristic of the photovoltaic module or cell is positive on the left side of the maximum power point, negative on its right side, and zero at the MPP (see figure 4). $P_{P V}$ and $V_{P V}$ are respectively the output power and voltage of the PV module or cell.

$$
\frac{\partial P_{P V}}{\partial V_{P V}}=0
$$

During the process of performing the $\mathrm{P} \& \mathrm{O}$ MPPT technique, the output current and voltage of the photovoltaic module or cell are measured periodically in consecutive steps in order to calculate the corresponding output power and then its derivative with respect to voltage.

A PWM controller of the power converter adjusts the reference signal Vref Figure 1, according to the sign of $\frac{\partial P_{P V}}{\partial V_{P V}}$, during the MPPT process in equation 8 :

$$
V_{r e f}(k)=V_{r e f}(k-1)+\alpha \operatorname{sign}\left(\frac{\partial P_{P V}}{\partial V_{P V}}(k)\right)
$$

$\mathrm{k}, \mathrm{k}-1$; are time steps at instant $\mathrm{t}$ and $\mathrm{t}-1$, $\alpha>0$; is a constant which determines the speed of convergence towards the point of maximum power.

We can use either a proportional integral (PI) or a fuzzy logic controller to regulate the output voltage of photovoltaic module or cell to the reference value Vref defined in equation 8 . A fuzzy logic controller has the advantage to give the best response time under dynamic conditions [17]. In steady state, the operating point of the PV module or cell oscillates around the MPP with an amplitude determined by 
the value of the constant $\alpha$ in equation 8. An increase in the disturbance step converges the operating point more rapidly towards the maximum point power under conditions of climatic variation (solar radiation and /or ambient temperature) and increases the oscillations around the MPP. This leads to a loss of energy.

Equation 8 can be developed to implement an MPPT system based on the $\mathrm{P} \& \mathrm{O}$ technique as an algorithm that can be executed by a digital signal processing unit (DSP) or by a microcontroller. Figure 4 illustrates the algorithm of the MPPT P\&O technique based on the procedure proposed by Hua \& al. [18]. It is also possible to use mixed signal circuits to implement the technique of perturbation and observation $\mathrm{P} \& \mathrm{O}$.

The algorithm illustrated in Figure 4 is run iteratively until the value of the derivative $\frac{\partial P_{P V}}{\partial V_{P V}}$ is less than a predefined threshold value, which indicates that the operating point converges to the MPP with the desired precision.

For the design of the control unit so that the process of the technique P\&O MPPT functions with the optimal values of the perturbation period and the step size, a method has been proposed by Blaabjerg \& al. [19].

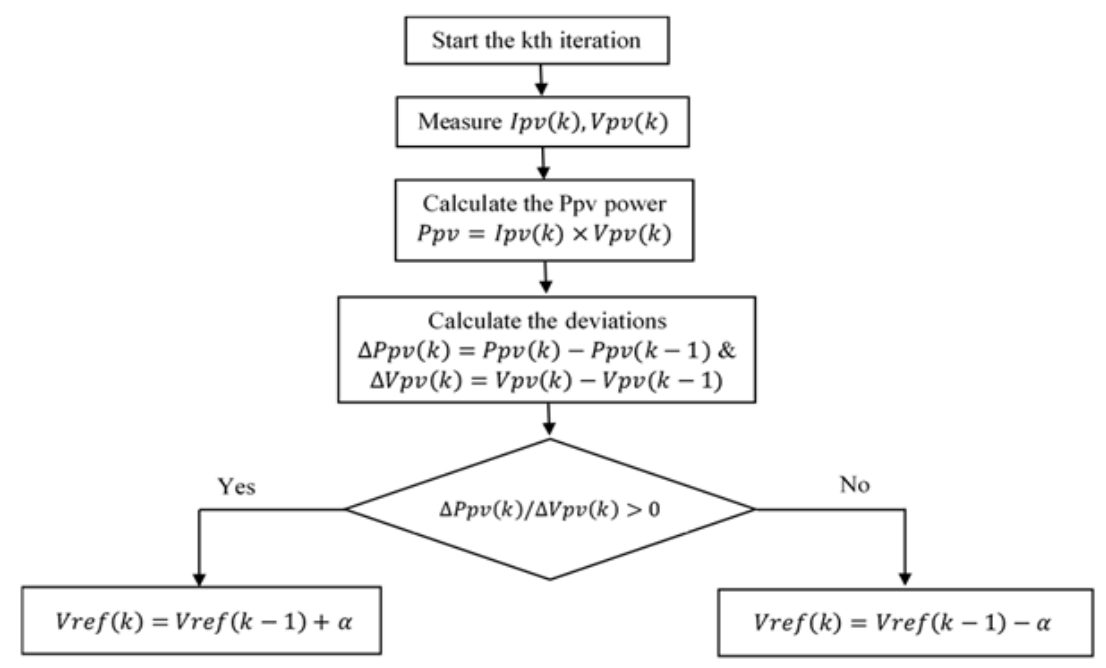

Figure 4. An algorithm of the MPPT perturbation and observation P\&O technique proposed by Hua et al. [19].

\section{Proposed Neural Networks MPPT Algorithm}

An optimized efficient hybrid technique for the maximum power point tracking (MPPT) of a PV module or cell is proposed figure 5. To track the maximum power point of a PV module or cell, an MPPT technique based on hybridization of Artificial Neural Networks (ANN) was developed to drive the trigger of the DC-DC converter switch through a periodic cycle.

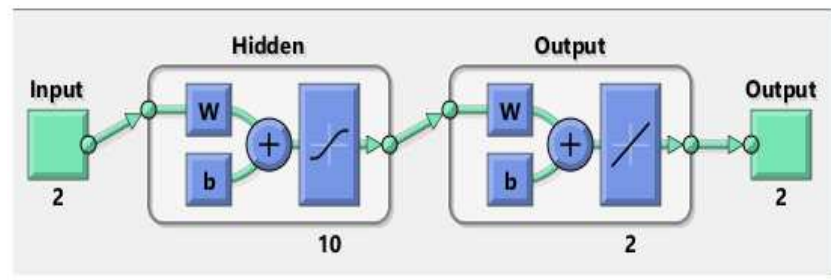

Figure 5. Architecture of the network.

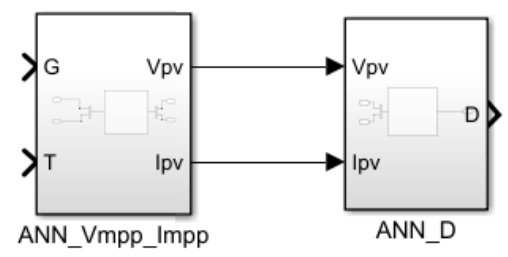

Figure 6. The proposed ANN hybrid controller.
The efficiency of artificial neural networks in system identification and adaptive controls makes them well suited to photovoltaic system applications especially in the pursuit of the maximum power point. A multi-layered perceptual neural network formed by the feedback propagation learning algorithm is the technique most used in engineering applications. A first non-recurrent multilayer neuron network was developed to estimate the optimum current and voltage at the maximum power point (MPP) taking into account the variation of irradiation and ambient temperature; and a second multilayer network to estimate the periodic cycle which will adjust the DC/DC converter switch.

The architecture of the first multilayer neural network is composed of three layers. The input layer made up of two neurons seen as there are two inputs which are solar irradiation and ambient temperature. The hidden layer made up of ten neurons; this number is obtained by applying the empirical rule, that is of starting to choose a high number of neurons and gradually eliminating them until you reach a more stable network and more precise outputs. The output layer comprising two neurons which are the optimum voltage and current corresponding to the maximum power point, Figure 5 illustrates the architecture of this network.

The data for the training of the artificial neural network is collected from the measurements of a significant amount during the real-time operation of the PV modules. The temperature $(\mathrm{T})$ between $10^{\circ} \mathrm{C}$ to $40^{\circ} \mathrm{C}$ with the step equal to 
$5^{\circ} \mathrm{C}$ and the solar irradiation $(\mathrm{G})$ between 200 to $1000 \mathrm{~W} / \mathrm{m}^{2}$ with a step equal to $25 \mathrm{~W} / \mathrm{m}^{2}$. The database is used for the formation of two networks.

The dataset is used for training the two neural networks, it has been shared into learning, testing and validation data. To obtain stable and precise neural networks, the trained artificial neural network models are continuously adjusted after each training and the results are tested and recorded. In the event of convergence, a performance factor determines the performance of the networks. Validation data is used to monitor the performance of models. If the network performance is quite correct on both the test and validation data, the networks can be considered accurate in generating the optimum voltage and current or the periodic cycle while excited by one of these inputs $(G, T)$ or $\left(V_{M P P}, I_{M P P}\right)$.

\section{Simulation Studies}

The Matlab/Simulink simulation tool is used for the complete simulation of the model produced. The MSX-60 PV module with the characteristic shown in the following table 1 was used. For validation, our model was compared to the classical model of Perturbation and Observation P\&O (figure 6).

Table 1. Specific Data Of MSX-60 PV Module.

\begin{tabular}{ll}
\hline Parameters & Values \\
\hline VOC & $21.06 \mathrm{~V}$ \\
ISC & $3.80 \mathrm{~A}$ \\
Current at Pmax (IMPP) & $3.80 \mathrm{~A}$ \\
Voltage at Pmax (VMPP) & $17.10 \mathrm{~V}$ \\
Power Maximal (PMPP) & $60.63 \mathrm{~W}$ \\
Coef de la temperature (VOC) (KV) & $-0.084 \mathrm{~V} / \mathrm{C}$ \\
Coef de la temperature (ISC) (KI) & $3.310^{\wedge}-4 \mathrm{~A} / \mathrm{C}$ \\
\hline
\end{tabular}
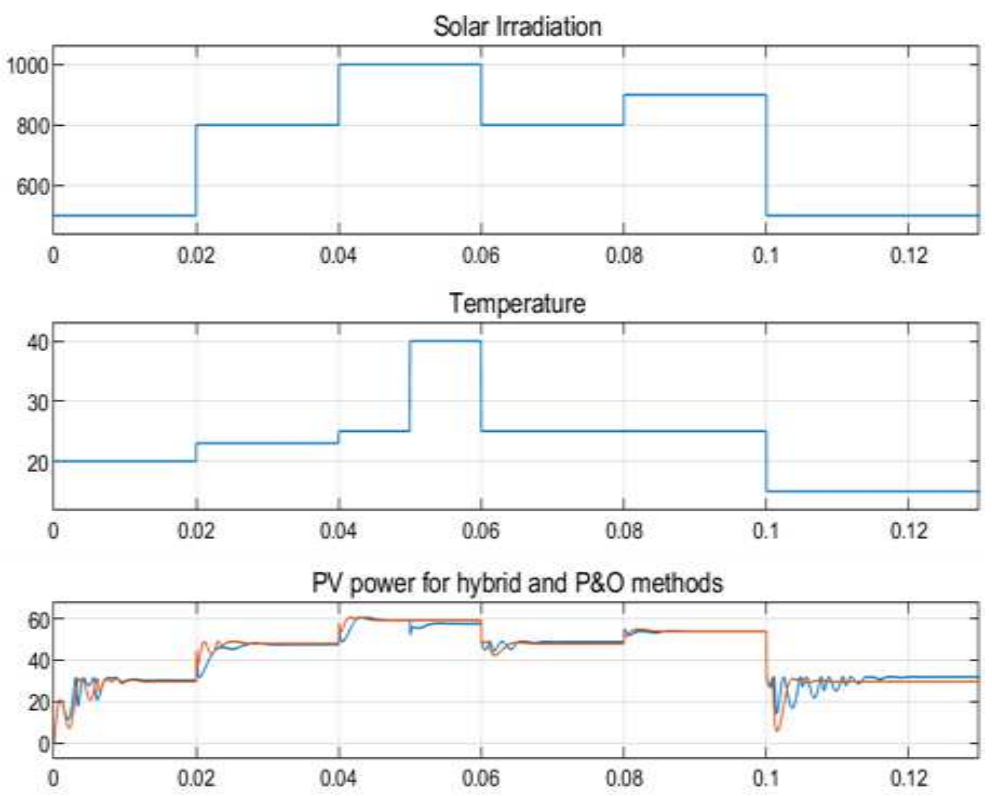

Figure 7. $P V$ array output power $P \mid \& O$ and hybrid MPPT controller under variable solar irradiation and temperature.
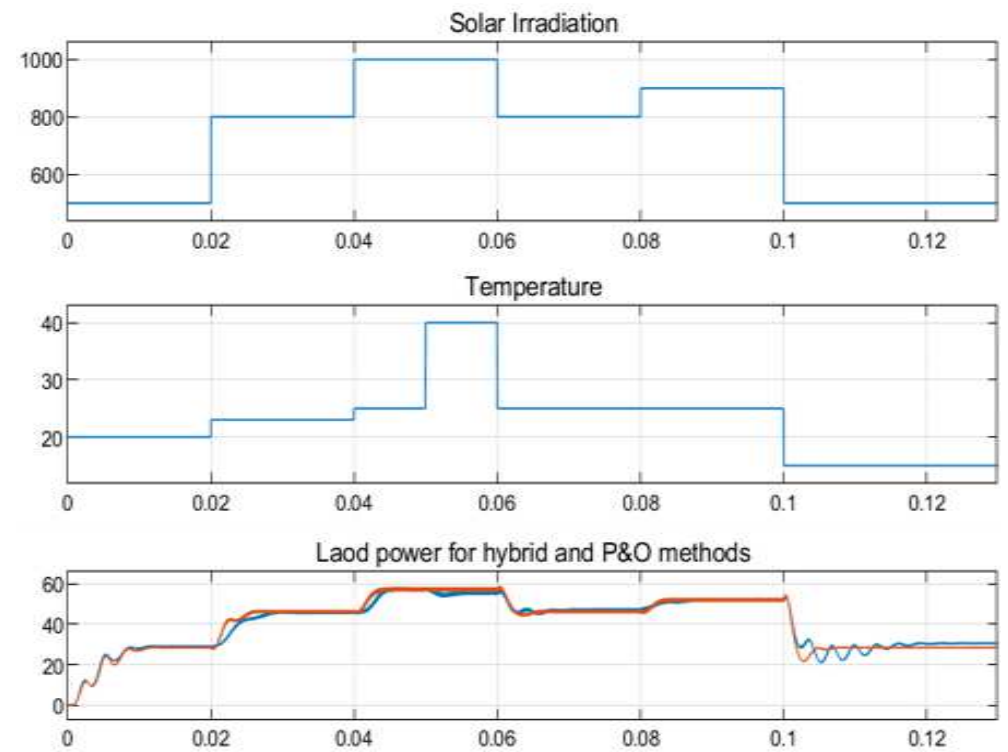

Figure 8. Load input power for $P \mid \& O$ and hybrid MPPT controller under variable solar irradiation and temperature. 


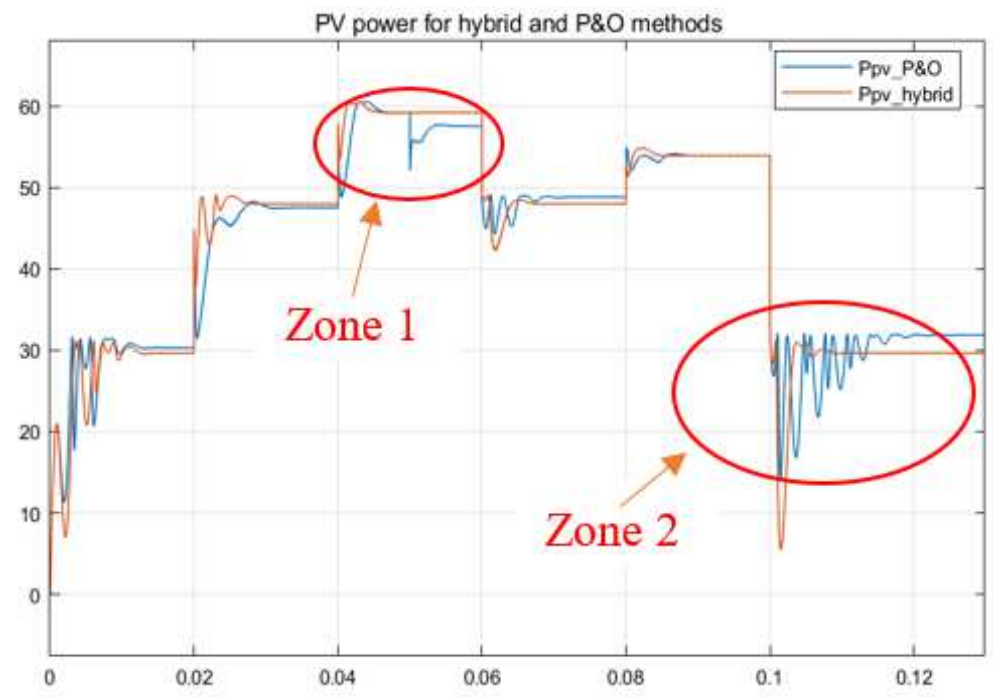

Figure 9. $P V$ power for hybrid and $P \mid \& O$ (a) MPPT under variable solar irradiation and temperature.

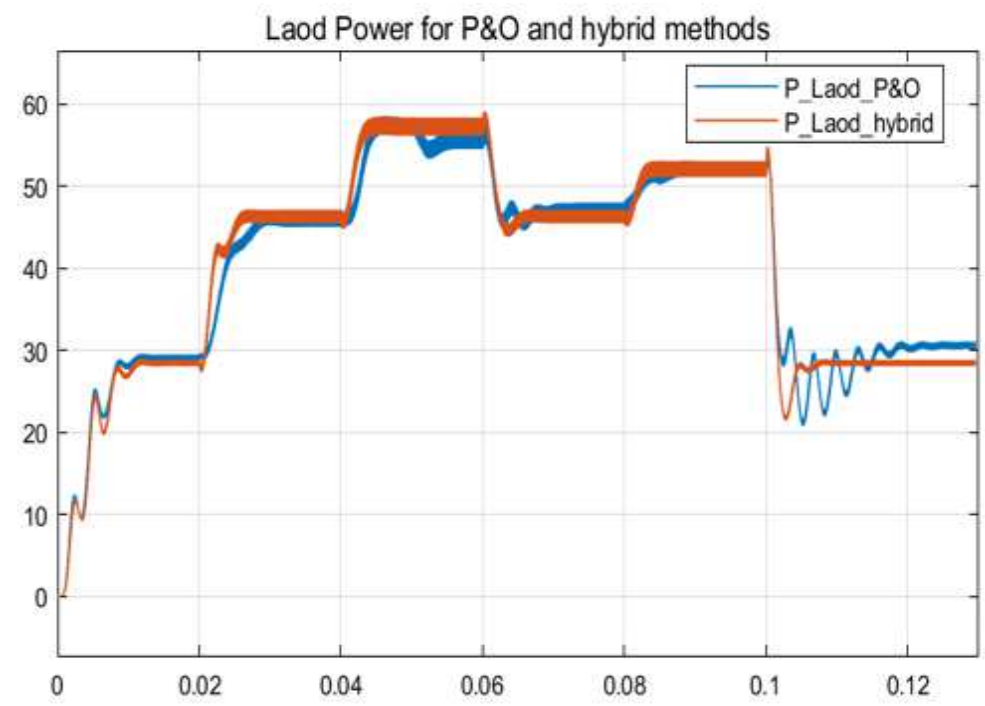

Figure 10. Load power for hybrid and $P \& O$ (a) MPPT under variable solar irradiation and temperature.

We tested and validated our hybrid MPPT technique based on the Artificial Neuron Network using the Matlab / Simulink modeling and simulation tool considering the variations of solar irradiation and ambient temperature, the results are illustrated on Figures 7 to 10.

1) MPPT tracking

The figures show the maximum power point tracking curves of the Perturbation and the Observation P\&O MPPT technique and the hybrid MPPT technique based on the proposed Artificial Neuron Network under the variation conditions of solar irradiation and ambient temperature. It can notice that in both cases, the results obtained by the hybrid MPPT technique are very close to the theoretical value corresponding to solar irradiation and temperature. Therefore, the hybrid MPPT technique proposed in this article is precise and stable compared to the Perturbation and Observation technique.

2) Response time

In Figure 9, we can observe that the response time of the proposed hybrid MPPT technique is significantly lower than that the response time P\&O MPPT technique. Consequently, the proposed hybrid MPPT algorithm has a better response time in tracking, especially around the point of maximum power.

3) Overshoot

From figure 9, it can be noticed that the quality of the output power PPV (overshoot) of the hybrid MPPT technique in the event of a sudden change (decrease or increase) of solar irradiation has very good performance in terms of overshoot power and response time.

4) ANN-MPPT ripple

According to figure 9 (zone 2), the ripple due to sudden variations in climatic conditions is much more improved in the hybrid MPPT technique. We can also observe that the quality of the output power $P_{P V}$ (with regard to ripple) is evident.

5) Therefore, P\&O MPPT method depends of the variation ambient temperature that ANN MPPT hybrid method (figure 9 zone 1). 


\section{Conclusion}

In this work, the application of Artificial Neural Network for maximum power point tracking was presented, as our contribution. The simulation is made under the conditions of variation of solar irradiation and ambient temperature. Figures 7, 8, 9 and 10 illustrate the different results, we can clearly see that among the two algorithms, the hybrid neural network system algorithm gives values closer to the theoretical values and more precise. We also find that the response time of RNA-hybrid is shorter than the Perturbation and observation P\&O. In addition, the proposed hybrid algorithm tracks the maximum power point more quickly during different conditions variations. The quality of the output power of the PV module for the ANN-hybrid approach exhibits a very good performance in the event of a sudden change in solar irradiation in terms of: response time and overshoot figure 8 . In addition, the $\mathrm{P} \& \mathrm{O}$ technique is more dependent on temperature than the ANN-hybrid technique Figure 9 (zone 1).

The results of this hybrid approach of neural networks are better compared to the classical method of perturbation and observation $\mathrm{P} \backslash \& \mathrm{O}$ in terms of response time, overshoots and rapid stabilization around the MPP point during sudden changes in solar irradiation and ambient temperature.

\section{References}

[1] Ahmed, J., \& Salam, Z. (2016). A modified $\mathrm{P} \backslash \& O$ maximum power point tracking method with reduced steady-state oscillation and improved tracking efficiency. IEEE Transactions on Sustainable Energy, 7 (4), 1506-1515.

[2] Veerachary, M., \& Shinoy, K. S. (2005). V2-based power tracking for nonlinear PV sources. IEE Proceedings-Electric Power Applications, 152 (5), 1263-1270.

[3] Mattia Ricco, Patrizio Manganiello, Giovanni Petrone, Eric Monmasson, and Giovanni Spagnuolo (2014). Fpga-based implementation of an adaptive $\mathrm{P} \& \mathrm{O}$ mppt controller for $\mathrm{pv}$ applications. In 2014 IEEE 23rd International Symposium on Industrial Electronics (ISIE), pages 1876\1881. IEEE.

[4] Kollimalla, S. K., \& Mishra, M. K. (2014). Variable perturbation size adaptive P\&O MPPT algorithm for sudden changes in irradiance. IEEE Transactions on Sustainable Energy, 5 (3), 718-728.

[5] Elgendy, M. A., Zahawi, B., \& Atkinson, D. J. (2012). Assessment of the incremental conductance maximum power point tracking algorithm. IEEE Transactions on sustainable energy, 4 (1), 108-117.

[6] Farhoodnea, M., Mohamed, A., Shareef, H., \& Zayandehroodi, H. (2013, June). Optimum D-STATCOM placement using firefly algorithm for power quality enhancement. In 2013 IEEE 7th international power engineering and optimization conference (PEOCO) (pp. 98-102). IEEE.
[7] Sera, D., Mathe, L., Kerekes, T., Spataru, S. V., \& Teodorescu, R. (2013). On the perturb-and-observe and incremental conductance MPPT methods for PV systems. IEEE journal of photovoltaics, 3 (3), 1070-1078.

[8] Ramasamy, A., \& Vanitha, N. S. (2014, January). Maximum power tracking for $\mathrm{PV}$ generating system using novel optimized fractional order open circuit voltage-FOINC method. In 2014 International Conference on Computer Communication and Informatics (pp. 1-6). IEEE.

[9] Afghoul, H., Krim, F., Chikouche, D., \& Beddar, A. (2013, May). Tracking the maximum power from a PV panels using of Neuro-fuzzy controller. In 2013 IEEE International Symposium on Industrial Electronics (pp. 1-6). IEEE.

[10] Xu, W., Mu, C., \& Jin, J. (2014). Novel linear iteration maximum power point tracking algorithm for photovoltaic power generation. IEEE Transactions on Applied Superconductivity, 24 (5), 1-6.

[11] Safari, A., \& Mekhilef, S. (2010). Simulation and hardware implementation of incremental conductance MPPT with direct control method using cuk converter. IEEE transactions on industrial electronics, 58 (4), 1154-1161.

[12] Reisi, A. R., Moradi, M. H., I\& Jamasb, S. (2013). Classification and comparison of maximum power point tracking techniques for photovoltaic system: A review. Renewable and sustainable energy reviews, 19, 433-443.

[13] Moo, C. S., \& Wu, G. B. (2014). Maximum power point tracking with ripple current orientation for photovoltaic applications. IEEE Journal of Emerging and Selected Topics in Power Electronics, 2 (4), 842-848.

[14] Malek, H., \& Chen, Y. (2014, March). A single-stage three-phase grid-connected photovoltaic system with fractional order MPPT. In 2014 IEEE Applied Power Electronics Conference and Exposition-APEC 2014 (pp. 1793-1798). IEEE.

[15] Toure, A. F., Addouche, S. A., Danioko, F., Diourte, B., \& Mhamedi, A. E. (2019). Hybrid Systems Optimization: Application to Hybrid Systems Photovoltaic Connected to Grid. A Mali Case Study. Sustainability, 11 (8), 2356.

[16] Di, X., Yundong, M., \& Qianhong, C. (2014, August). A global maximum power point tracking method based on interval short-circuit current. In 2014 16th European Conference on Power Electronics and Applications (pp. 1-8). IEEE.

[17] El Khateb, A., Abd Rahim, N., Selvaraj, J., \\& Uddin, M. N. (2014). Fuzzy-logic-controller-based SEPIC converter for maximum power point tracking. IEEE Transactions on Industry Applications, 50 (4), 2349-2358.

[18] Hua, C., Lin, J., \& Shen, C. (1998). Implementation of a DSP-controlled photovoltaic system with peak power tracking. IEEE Transactions on Industrial Electronics, 45 (1), 99-107.

[19] Blaabjerg, F., \& Ionel, D. M. (Eds.). (2017). Renewable energy devices and systems with simulations in matlab ${ }^{\circledR}$ and ansys ${ }^{\circledR}$. CRC Press. 